the right side was diagnosed on chest radiography; antibacterial therapy (ceftazidime, levofloxacin) has been prescribed. On a background of treatment the temperature has decreased to subfebrile. 06.07 at X-ray revealed a negative dynamics with the spread of infiltration to the lower parts of the left lung. She was hospitalized in pulmonology department. From the past diseases - genital herpes, chronic tonsillitis. Harmful habits, allergic reactions, professional harmfulness denies.

The patient's condition is satisfactory; Skin and mucous membranes are clean, of normal color. Respiratory rate 17 in min. Percussion sound over the lungs is pulmonary. Vesicular breathing, crepitus in the lower parts on both sides, more on the left. Blood pressure 100/60 mm/Hg Heart auscultation: tones are clear, rhythmic, heart rate -80 per min. The tongue is wet.

The abdomen is painless. Liver: $9 \times 8 \times 7 \mathrm{~cm}$, the edge of liver is even. The kidneys are not palpable. The lumbar region is painless on both sides.

In the clinical blood test there was an increase in ESR up to $60 \mathrm{~mm} / \mathrm{h}, \mathrm{CRP}-37.4 \mathrm{mg} / \mathrm{L}$, procalcitonin $<0.5 \mathrm{ng} / \mathrm{ml}$. Other parameters are within the normal range. The patient was examined by CT of thoracic organs. On a series of tomograms, in S8 - S10 on both sides determined uneven compaction of pulmonary tissue due to infiltrative changes, against which background bronchial lumens are traced. A wide base of infiltration adjoins the pleura, and narrow - directed towards the root of the lung. Given the clinical picture, the progression of the disease against the background of antibacterial therapy, high density of infiltrates in the lungs, doubts were expressed regarding bacterial pneumonia.

Interstitial lung disease was more likely. 09.07 there was held video-thoracoscopy in the left, biopsy of the lower lobe of the left lung. Pathological conclusion: the lung tissue is deformed due to ingrowth of the respiratory bronchioles of the 1st order of granulation tissue in the form of polyps in the part of the alveoli cavity and in the part of the alveolar cavities - the accumulation of macrophages with an admixture of eosinophils and red blood cells with individual eosinophils, in other lumens alveolus is a fibrin accumulation with an admixture of eosinophils and neutrophils, the individual walls of the alveoli are thickened due to the small lymphocytic infiltration and proliferation of second type alveolocytes. Conclusion: obliterating respiratory bronchiolitis with organizing pneumonia. Arteriolar walls Fibroelastosis.

Based on the results of the examination, the patient was diagnosed with: Cryptogenic organizing pneumonia (obliterating bronchiolitis with organizing pneumonia). By this time, the patient's well-being improved - the temperature returned to normal, the dyspnea disappeared. Systemic corticosteroid therapy (prednisolone $25 \mathrm{mg} /$ day) has been started. In 2 weeks. there was further positive dynamics: no complaints, a decrease in ESR up to $42 \mathrm{~mm} / \mathrm{h}$, on CT of the chest - a decrease in the size and density of infiltrates in the lungs. In another 2 months. infiltration into lung tissue was no longer determined.

Idiopathic interstitial pneumonia combines several diseases from the group of interstitial lung diseases characterized by many similar features. Modern classification of ATS / ERS includes seven forms of IIP. The morphological substrate of COP is obliterative bronchiolitis with organizing pneumonia, characterized by the organization of exudate and fibroblastic reaction in the form of granulation tissue ingrowth into respiratory bronchioles, alveolar courses and alveoli.

The COP included in the classification of in respect of its idiopathic nature and similar to other forms of IIP, especially if the IIP progressestofibrosis. ACOPusuallyhasasubacutecourse with a relativelyshortperiod beforediagnosis(average 3 months), with a cough and shortness of breath of varying severity. The most common causes of OBOP are infection, drugs, radiation therapy and diseases of the connective tissue. If the cause is not obvious, OBOP called cryptogenic organizing pneumonia.

Conclusions. The clinical pattern of a COP is very similar to bacterial pneumonia. The disease has acute or subacute beginning, accompanied by fever, cough, and appearance finely wheezing in the areas of infiltration. Characteristically by the development of dyspnea from the first days of the disease. The standard of treatment of COP is the prescription of systemic corticosteroid - prednisolone at a dose of $0.75-1.5 \mathrm{mg} / \mathrm{kg}$ daily for $1-3$ months. Despite the generally good response to steroid therapy, $30-50 \%$ of patients after discontinuation of hormonal therapy relapse occurring in a milder form. Fiveyears survival rate in this disease is $90 \%$. The COP is one of the variants of reaction of the lungs to an infectious factor and can occur heterogeneous in different patients, from complete resolution to progressive course and formation of fibrosis.

\title{
References
}

1. Avdeev S. N. Idiopathic interstitial pneumonias: features of clinical picture and treatment // Farmateka, 2009. No. 19.

2. Avdeev S. N. Different variants of the course of idiopathic pulmonary fibrosis: phenotypes and comorbid conditions // Practical pulmonology, 2016. No. 2. P. 37 - 45.

UDC 612-017.2:613.166/.9]616-003.96:577.118 DOI 10.22448/AMJ.2017.3.135-137

\section{APPLICATION PHYTOADAPTOGENS FOR THE CORRECTION OF PHYSICAL LOADS ON THE BODY UNDER TEMPERA- TURE STRESS}

\author{
Litovchenko E.A., Korshunova N.V.
}

Amur State Medical Academy, 95 Gor'kogo Str., Blagoveshchensk, 675000, Russian Federation

Abstract In the experimental conditions investigated the possibility of increasing the resistance of rats to physical influence in the conditions of use of a mixture of adaptogenic products (Hypericum perforatum and Rhodiola rosea) in cold and heat stress. 
Key words: heat stress, cold stress, fatigue, physical performance, resistance.

Objective To identify the possibility of increasing the resistance of experimental animals to physical impact in terms of the studied mixture of adaptogenic products of Hypericum perforatum and Rhodiola rosea in cold and heat stress.

Materials and methods The animals were divided into 9 groups, each of them had 10 rats: 1 -intact animals which were held in standard conditions of vivarium; 2 -the control group in which rats were exposed to cold during three hours daily (-150 C, 50\% humidity); 3 - the control group in which rats were exposed to heat during 45 minutes daily (+400 C, 50\% humidity); 4,6,8 - the experimental groups in which before cooling animals had a daily intake of powder mixture of Hypericum perforatum and Rhodiola rosea in a dose of $30 \mathrm{mg} / \mathrm{kg}, 150 \mathrm{mg} / \mathrm{kg}, 300 \mathrm{mg} / \mathrm{kg}$ respectively; $5,7,9$ - the experimental groups in which rats before putting them in the heat climatically were a daily intake of powder mixture of Hypericum perforatum and Rhodiola rosea in a dose of $30 \mathrm{mg} / \mathrm{kg}, 150 \mathrm{mg} / \mathrm{kg}, 300 \mathrm{mg} / \mathrm{kg}$ respectively.

Results and discussion It was found out that cold and heat exposure reduces the resistance of experimental animals (in different degrees) to swim all the days of the experiment (table 1,2). The introduction of a mixture of Hypericum perforatum and Rhodiola rosea in animal feed in a dose of $150-300 \mathrm{mg} / \mathrm{kg}$, which were exposed to temperature effects, increased swimming time up to $178 \pm 4,7(\mathrm{~min})$ and $181 \pm 3,0(\mathrm{~min})$, herewith time of intact rats were $146 \pm 3,4$ ( $\mathrm{min})$; control group which were put to cold exposure $108 \pm 5,6(\mathrm{~min})$, and heat $105 \pm 3,4(\mathrm{~min})(\mathrm{p}<0.01)$. On the 14th day the average duration of swimming of rats, which used the studied compound at a dose of $150-300 \mathrm{mg} / \mathrm{kg}$, was $192 \pm 3,0(\mathrm{~min})$ and $188 \pm 5.9(\mathrm{~min})$. A similar trend is observed until the 28 th day of observation.

Table 1 The duration of the voyage rats (in minutes) during prolonged cold stress and the using a mixture of Hypericum perforatum and Rhodiola rosea $(M \pm m, n=10)$

\begin{tabular}{|l|l|l|l|c|}
\hline Groups of animals & 7 th day & 14 th day & 21 st day & 28 th day \\
\hline Intact & $146 \pm 3,4$ & $153 \pm 6,3$ & $156 \pm 4,6$ & $161 \pm 5,0$ \\
\hline Control - cold & $108 \pm 5,6^{*}$ & $114 \pm 3,3^{*}$ & $124 \pm 4,3^{*}$ & $127 \pm 3,1^{*}$ \\
\hline Experimental - cold $+30 \mathrm{mg} / \mathrm{kg}$ of the mixture & $110 \pm 5,8$ & $118 \pm 6,4$ & $118 \pm 2,5$ & $120 \pm 5,4$ \\
\hline Experimental - cold $+150 \mathrm{mg} / \mathrm{kg}$ of the mixture & $178 \pm 4,7^{* *}$ & $192 \pm 3,0^{* *}$ & $194 \pm 6,3^{* *}$ & $202 \pm 3,6^{* *}$ \\
\hline Experimental - cold $+300 \mathrm{mg} / \mathrm{kg}$ of the mixture & $217 \pm 3,4^{* *}$ & $241 \pm 7,3^{* *}$ & $254 \pm 5,5^{* *}$ & $268 \pm 4,7^{* *}$ \\
\hline
\end{tabular}

Note: here and in the following table ${ }^{*}$ and ${ }^{* *}$ values significantly different from the values of intact ${ }^{*}$ and subjected to cold and heat stress $* *$ groups of animals $(p<0,05)$

Table 2

The duration of the voyage rats (in minutes) during prolonged heat stress and the using a mixture of Hypericum perforatum and Rhodiola rosea $(M \pm m, n=10)$

\begin{tabular}{|l|l|l|l|l|}
\hline Groups of animals & 7 th day & 14 th day & 21 st day & 28 th day \\
\hline intact & $146 \pm 3,4$ & $153 \pm 6,3$ & $156 \pm 4,6$ & $161 \pm 5,0$ \\
\hline Control - heat & $105 \pm 3,4^{*}$ & $112 \pm 2,6^{*}$ & $117 \pm 5,7^{*}$ & $129 \pm 4,0^{*}$ \\
\hline Experimental - heat $+30 \mathrm{mg} / \mathrm{kg}$ of the mixture & $107 \pm 3,2$ & $117 \pm 4,3$ & $118 \pm 4,6$ & $127 \pm 3,0$ \\
\hline Experimental - heat $+150 \mathrm{mg} / \mathrm{kg}$ of the mixture & $181 \pm 3,0^{* *}$ & $188 \pm 5,9^{* *}$ & $193 \pm 4,3^{* *}$ & $199 \pm 2,7^{* *}$ \\
\hline Experimental - heat $+300 \mathrm{mg} / \mathrm{kg}$ of the mixture & $210 \pm 6,2^{* *}$ & $220 \pm 4,4^{* *}$ & $236 \pm 3,3^{* *}$ & $261 \pm 3,6^{* *}$ \\
\hline
\end{tabular}

Thus, the use of a mixture of Hypericum perforatum and Rhodiola rosea in conditions of prolonged heat and cold stress on the organism of experimental animals leads to significant increase in the resistance of rats to fatigue.

References:

1. Borisova L.B., Selfulla R.D., Zhuravlev A.I. The effect of antioxidants on physical work capacity and lipid peroxidation in the body. Farmakologiya i toksikologiya 1990; 4: 89-92 (in Russian).

2. Kozyreva T.V. Adaptive changes in temperature sensitivity of the person in conditions of cold, heat and physical exercise. Fiziologiya cheloveka 2006; 32(6):103-108 (in Russian).

3. Korshunova N.V. Toxicological-hygienic substantiation of use of products of processing of antlers to increase the resistance of the organism to cold: dissertation of doctor of science. Sankt-Peterburg; 2001 (in Russian).

136 Амурский медицинский журнал №3 (19) 2017 
4. Pavlova T. V., Pavlov A. S. Morphological and physiological indicators of thermal adaptation. Fiziologiya cheloveka 1992; 18(2):108-113 (in Russian).

5. Panin L.E., Kuz'menko D.I. The role of nutrition in the alteration of energy metabolism under stress. Voprosy pitaniya 1982; 3:15-18 (in Russian).

Ekaterina A.Litovchenko Full-time graduate student in the Department of General hygiene

Amur state medical Academy Ministry of health of the Russian Federation 95 Gor'kogo Str., Blagoveshchensk, Amur region, Russian Federation, 675000 Tel. 89638166713, 89246774281 E-mail: ekaterinalitovchenko-89@mail.ru

Natalia V. Korshunova Head of the Department of General Hygiene, doctor of medical Sciences, Professor of the Department of

General hygiene Federal State budgetary educational institution of higher education Amur state medical Academy Ministry of

health of the Russian Federation 95 Gor'kogo Str., Blagoveshchensk, Amur region, Russian Federation, 675000 Tel. 89143893760

UDC 616.248 - 084:618.2 - 06 DOI 10.22448/AMJ.2017.3.137-138

\title{
THE INFLUENCE OF FOLATES METABOLISM GENES ON THE COURSE OF ASTHMA DURING PREGNANCY
}

\author{
Luchnikova T.A., Voitsekhovsky V.V., Prikhodko O.B.
}

Amur State Medical Academy, Blagoveschensk, Russia

Abstracts. The Bronchial asthma (BA) is one of the most urgent problems of pulmonology, at the same time continuous increase in number of patients around the world is noted. Purpose of the research is to determine the influence of genetic polymorphisms of the folates metabolism on asthma course during pregnancy. We are examined 96 pregnant women with BA: from them at 33 patients - controlled BA, at 39 - partially controllable, at 24 - uncontrollable. At 47 patients have a mild current, at 43 - moderate and at 6 - a severe asthma the comparison group consisted of 26 pregnant women without bronchopulmonary pathology.

Key words: bronchial asthma, pregnancy, folates metabolism genes

The Bronchial asthma (BA) is one of the most urgent problems of pulmonology, at the same time continuous increase in number of patients around the world is noted. Study of the question of mutual complication of bronchial asthma (BA) and pregnancy remains relevant due to the increase of the prevalence of asthma in reproductive age women. Parrticular interest is the educational systemic inflammation in asthma, since asthma is an inflammatory process in the bronchial tree. Endothelial dysfunction is a participate in any inflammatory process and can be considered as one of the possible pathogenetic mechanisms of the formation of this disease.

Purpose of the research is to determine the influence of genetic polymorphisms of the folates metabolism on asthma course during pregnancy.

Material and methods. We are examined 96 pregnant women with BA: from them at 33 patients - controlled BA, at 39 - partially controllable, at 24 - uncontrollable. At 47 patients have a mild current, at 43 - moderate and at 6 - a severe asthma the comparison group consisted of 26 pregnant women without bronchopulmonary pathology.

The materials for the molecular and genetic research were DNA samples of 52 pregnant women with asthma and 30 pregnant women without bronchopulmonary diseases (control group).

Results and discussion. During the assessing of frequency of occurrence of MTHFR 677TT genotype depending on the availability of asthma, it was found that in a group of pregnant women with asthma the genotype has been met authentically more frequent than in the control group $(p<0.05)$.

At the same time in case of presence of MTRR66GG gene risk of severe, atopic asthma is increased, the odds ratio (OR) was 9.5 (Cl 1.52, 59.05).

Correlation between allergic form of BA and the presence of the polymorphic genotype of C677T MTHFR ( $r=-0,31$; $p=0.02)$, and mutations in the gene MTRRA66G $(r=-0,30 ; p=0.02)$. The presence of mutations in the gene for MTHFR C677T is more frequently noted in allergic asthma.

In the presence of a polymorphic genotype 677TT asthma exacerbations during pregnancy are more common than in women with normal genotype 677SS ( $p=0.03$ ). The presence of the mutant allele 677T worsens the course of asthma during pregnancy. The relative risk (RR) of asthma worsening in the period of gestation was $5.13(\mathrm{Cl} 0.68,38.62)$. It was found that in pregnant women with of asthma who have MTHFR 677TT and MTRR66GG genes, threatened miscarriage, preeclampsia, chronic fetoplacental insufficiency, chronic fetal hypoxia, fetal intrauterine growth retardation of varying severity are authentically more common. OR of pregnancy complications development if there is polymorphisms of folate metabolism genes MTHFR677TT and MTRR66GG is 6,29 (Cl 3.44, 11.27). The presence of the mutant allele MTRR66GG authentically reduces the indexes of newborn weight and height $(p=0.03)$. In newborns from mothers with asthma and polymorphic genotype MTHFR 677TT, perinatal CNS damage is detected more frequently than that in pregnant women with asthma and normal genotype by this gene. OR 1.66 (Cl 1.09, 2.53). OR of perinatal CNS lesion is $4.04(\mathrm{Cl} 1.33,12.27)$.

Homocysteine $(\mathrm{HZ})$ in a group of pregnant women with asthma was significantly higher than in the comparison group $(p<0.05)$. While the more hard proceeded BA, the higher the $\mathrm{HZ}$ level recorded in pregnant women. When hyperhomocysteinemia often marked by the deterioration of the dynamics of BA course in gestational period $(r=0.63, p<0.01)$ 